\title{
Silicon Carbide Semiconductors with Wide Bandgap for Electric Vehicles
}

Consumer demand for electric vehicles is steadily increasing - and so is the demand for new solutions to maximize vehicle range and reduce costs. United Silicon Carbide has developed silicon carbide semi-

conductors that can be used to realize more efficient electric powertrains and power devices. 


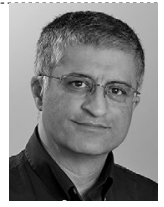

Anup Bhalla is Vice President of Engineering at United Silicon Carbide Inc. in Princeton (USA).

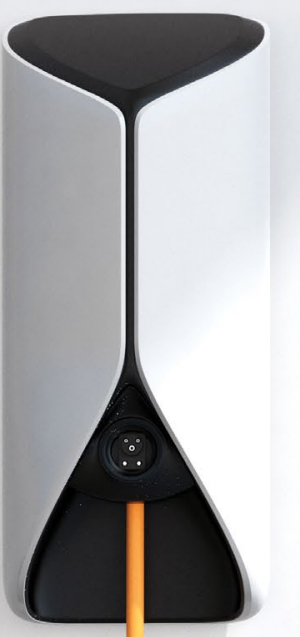

Electric cars are becoming increasingly popular due to falling prices and increasing ranges. Sales of electric cars topped 2.1 million globally in 2019 . According to [1], there were thus over 7.2 million electric passenger cars on the roads in 2019. However, continued growth depends on a number of factors including the continuation of purchase subsidy schemes in key markets and the impact of Covid-19 on automotive production. There is also the core challenge of developing the national charging infrastructures needed to support rapid and out-of-home charging.

\section{SEMICONDUCTOR WITH WIDE BANDGAP}

Battery and motor manufacturers are reaching the limits of physical performance that can be achieved using the established technologies, most notably those using silicon. In electric vehicles, the most crucial area in terms of efficiency is where the battery's DC voltage is converted into three-phase AC voltage for the motors. Wherever power is converted between DC and AC, especially at DC voltages in the region of $800 \mathrm{~V}$ required in electric vehicles, there is a significant potential for loss. The upgrade path here that most electric vehicle OEMs are exploring is to move from silicon to Wide-bandgap (WBG) semiconductors, such as Silicon Carbide ( $\mathrm{SiC}$ ) semiconductors.

With regard to power switching, SiC semiconductors have already offered many advantages for some time. For this reason, these semiconductors have been used in electric vehicles primarily for low-power applications, such as battery chargers, auxiliary DC/DC converters and solid-state circuit breakers. SiC semiconductors were not previously used for the powertrain, partly because the switch-on resistance was too high and the robustness too low. The current generation of SiC FETs from United Silicon Carbide is now also suitable for high power applications due to their stacked cascode design [2].

\section{DESIGN OF STACKED CASCODES}

A stacked cascode consists of the series connection of a high-voltage SiC JFET with an optimized low-voltage Si Mosfet, FIGURE 1. The Mosfet is switched on as soon as its gate voltage is high. This also short-circuits the gate and source of the JFET, so that it is forcibly switched on. When the gate voltage of the Mosfet drops low, its drain voltage rises, but only to the point where the JFET is turned off at about $15 \mathrm{~V}$. The result is a normallyoff device with an easy gate drive. Moreover, it has all the benefits of an $\mathrm{SiC}$ device with low on-resistance, high voltage and high-temperature operation, and an integral body diode effect with good reverse recovery characteristics.

Cascodes have been used for a long time already. Their development has resulted in cascode devices based on JFETs now achieving very low on-resistances, even at high voltages. This makes the cascode close to being the

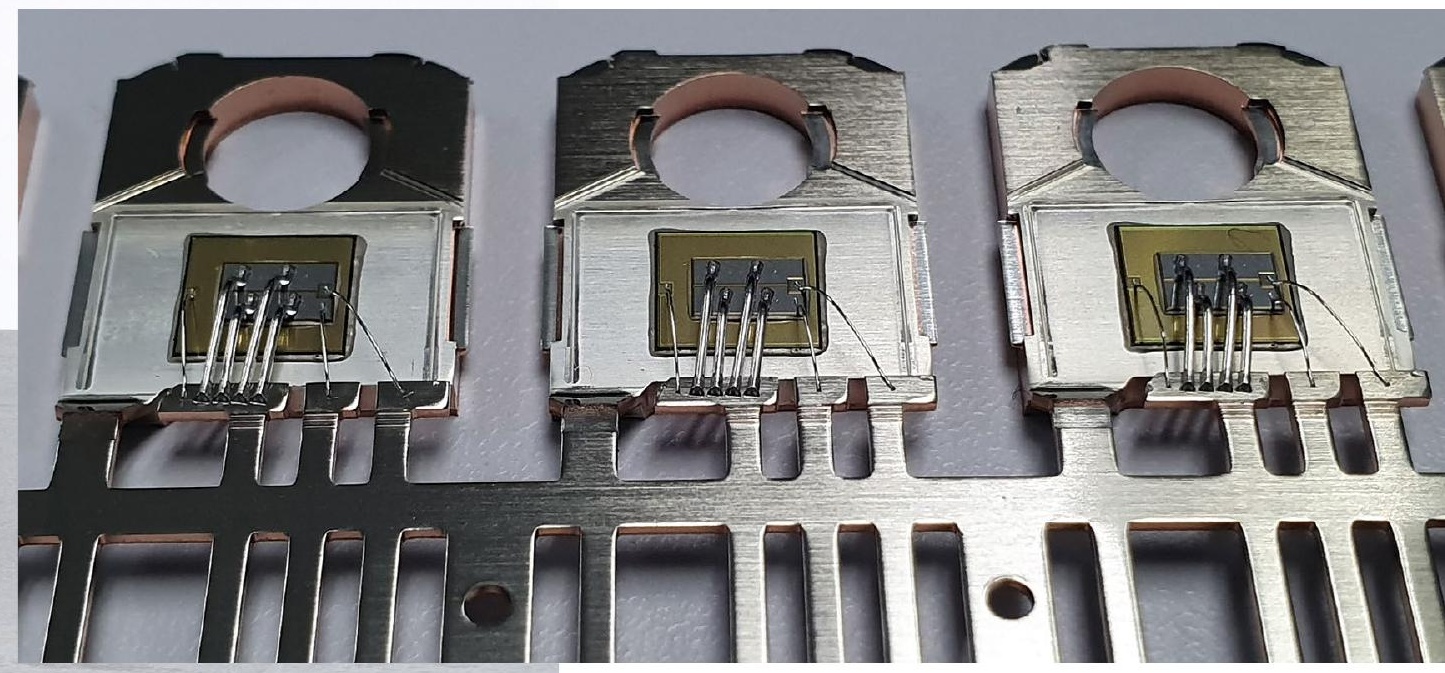

FIGURE 1 Layout of a stacked cascode - the Mosfet chip is physically stacked on the JFET source pad (@ UnitedSiC) 


\begin{tabular}{|c|c|c|c|c|c|c|c|c|c|c|c|}
\hline \multirow[t]{2}{*}{ SIC FET } & \multirow[t]{2}{*}{ Package } & \multirow{2}{*}{$\begin{array}{l}V_{\mathrm{DS}(\max )} \\
{[\mathrm{V}]}\end{array}$} & \multirow{2}{*}{$\begin{array}{l}\text { ID }\left(100^{\circ} \mathrm{C}\right) \\
{[A]}\end{array}$} & \multirow{2}{*}{$\begin{array}{l}\mathbf{R}_{\text {THJC(max) }} \\
{[K / \mathrm{W}]}\end{array}$} & \multirow{2}{*}{$\begin{array}{l}R_{\mathrm{DS}(\mathrm{ON})} \\
\left(25^{\circ} \mathrm{C}\right) \\
{[\mathrm{m} \Omega]}\end{array}$} & \multirow{2}{*}{$\begin{array}{l}\mathrm{R}_{\mathrm{DS}(\mathrm{ON})} \\
\left(125^{\circ} \mathrm{C}\right) \\
{[\mathrm{m} \Omega]}\end{array}$} & \multirow{2}{*}{$\begin{array}{l}\mathrm{R}_{\mathrm{DS}(\mathrm{ON})} \\
\left(175^{\circ} \mathrm{C}\right) \\
{[\mathrm{m} \Omega]}\end{array}$} & \multirow{2}{*}{$\begin{array}{l}C_{\text {oss }} \\
(800 \mathrm{~V}) \\
{[\mathrm{pF}]}\end{array}$} & \multirow{2}{*}{$\begin{array}{l}E_{\mathrm{ON}} \\
{[\mathrm{mJ}]}\end{array}$} & \multirow{2}{*}{$\begin{array}{l}E_{\text {off }} \\
{[\mathrm{mJ}]}\end{array}$} & \multirow{2}{*}{$\begin{array}{l}\text { Switching } \\
\text { conditions }\end{array}$} \\
\hline & & & & & & & & & & & \\
\hline UF3SC120009K4S & T0247-4L & 1200 & 120 & 0.19 & 8.6 & 13.3 & 18.2 & 395 & 3.5 & 0.7 & $\begin{array}{l}100 \mathrm{~A}, 800 \mathrm{~V} \\
\mathrm{HB} 150 \mathrm{C}\end{array}$ \\
\hline UF3SC120016K4S & T0247-4L & 1200 & 77 & 0,29 & 16 & 24.8 & 33 & 243 & 2.82 & 0.15 & $\begin{array}{l}80 \mathrm{~A}, 800 \mathrm{~V}, \\
\mathrm{HB} 150 \mathrm{C}\end{array}$ \\
\hline UF3SC120016K3S & T0247-3L & 1200 & 77 & 0.29 & 16 & 24,8 & 33 & 243 & 3,35 & 0.67 & $\begin{array}{l}80 \mathrm{~A}, 800 \mathrm{~V}, \\
\mathrm{HB} 150 \mathrm{C}\end{array}$ \\
\hline UF3SC065007K4S & T0247-4L & 650 & 120 & 0.19 & 6.7 & 8.7 & 11 & 865 & 1.08 & 0.1 & $\begin{array}{l}80 \mathrm{~A}, 400 \mathrm{~V}, \\
\mathrm{HB} 150 \mathrm{C}\end{array}$ \\
\hline
\end{tabular}

TABLE 1 Selection of SiC FETS $\left(R_{D S(O N)}\right.$ : drain-source on-resistance; $C_{O S s}$ : output capacitance; $E_{O N}$, $E_{O F F}$ : switching energy for on or off; $V_{D S(m a x)}$ : maximum drain-source voltage; $I_{D}$ : drain current; $R_{T H J C(m a x)}$ : maximum thermal junction resistance; HB: semiconductor junction (@ UnitedSiC)

ideal switch. TABLE 1 shows a selection of $\mathrm{SiC}$ FETs from UnitedSiC with $\mathrm{R}_{\mathrm{DS}(\mathrm{ON})}$ values as low as $8.6 \mathrm{~m} \Omega$ for a $1200-\mathrm{V}$ device and $6.7 \mathrm{~m} \Omega$ for a $650-\mathrm{V}$ device, respectively (both at $25^{\circ} \mathrm{C}$ ). All devices are integrated in TO-247 packages; some of the devices are equipped with four-wire Kelvin terminals for optimal gate drive.

\section{INDUCTIVE LOAD CONTROLS}

Systems that use semiconductor switches to control inductive loads, such as in motor drive applications, must also be capable of reversing the current flow. In circuits that use IGBTs, a high-volt- age parallel diode is normally necessary to facilitate this reverse current flow. This represents an extra cost. In order to preserve efficient operation the diodes also need to offer high performance, exhibiting minimal reverse recovery energy loss. Using SiC Mosfets can avoid the additional cost of adding a diode, as they have an integral reverse diode. Unfortunately, performance is relatively poor with a high forward voltage drop and significant recovery losses.

This is another application where using a SiC FET can improve performance. It also supports reverse current flow through the channel and with no reverse recovery effects. It also features low forward drop across the already low on-resistance. The stacked Si Mosfet also conducts in the reverse direction, but since it is an optimized low-voltage type, its body diode drop is small and contributes little in the form of recovery losses. The latest generation of SiC FETs is suitable for controlling inductive loads, with lower losses than the traditional IGBT approach and the added benefits.

TABLE 2 shows calculated losses at six power levels comparing a current state-of-the-art IGBT module and parallel diode approach with different SiC FETs. As TABLE 2 shows, SiC FETs

\begin{tabular}{|c|c|c|c|c|c|c|c|c|c|c|c|}
\hline \multirow{2}{*}{$\begin{array}{l}\text { Voltage } \\
\text { class }\end{array}$} & \multirow{2}{*}{$\begin{array}{l}\text { Component } \\
\text { type }\end{array}$} & \multirow[b]{2}{*}{ Chips/switch } & \multirow{2}{*}{$\begin{array}{l}\text { Bus } \\
\text { voltage }\end{array}$} & \multirow[b]{2}{*}{ Frequency } & \multirow[b]{2}{*}{ Loss type } & \multicolumn{6}{|c|}{ Power output } \\
\hline & & & & & & $50 \mathrm{~kW}$ & $100 \mathrm{~kW}$ & $150 \mathrm{~kW}$ & $200 \mathrm{~kW}$ & $250 \mathrm{~kW}$ & $300 \mathrm{~kW}$ \\
\hline \multirow{4}{*}{1200} & \multirow{4}{*}{$\begin{array}{l}\text { IGBT + } \\
\text { diode }\end{array}$} & \multirow{4}{*}{$100 \mathrm{~A} \times 4$ each } & \multirow{4}{*}{$800 \mathrm{~V}$} & \multirow{4}{*}{$8 \mathrm{kHz}$} & $\mathrm{P}_{\text {condition }}[\mathrm{W}]$ & 193 & 440 & 742 & 1097 & & \\
\hline & & & & & $\mathrm{P}_{\text {switching }}[\mathrm{W}]$ & 823 & 1191 & 1559 & 1927 & & \\
\hline & & & & & $P_{\text {total }}[W]$ & 1016 & 1613 & 2301 & 3024 & & \\
\hline & & & & & Efficiency [\%] & 97.97 & 98.37 & 98.47 & 98.49 & & \\
\hline \multirow{4}{*}{1200} & \multirow{4}{*}{ SiC FET } & \multirow{4}{*}{ UF3SC120009K4S $\times 4$} & \multirow{4}{*}{$800 \mathrm{~V}$} & \multirow{4}{*}{$8 \mathrm{kHz}$} & $P_{\text {condition }}[\mathrm{W}]$ & 67 & 270 & 608 & 1080 & & \\
\hline & & & & & $\mathrm{P}_{\text {switching }}[\mathrm{W}]$ & 185 & 218 & 261 & 313 & & \\
\hline & & & & & $P_{\text {total }}[W]$ & 252 & 488 & 869 & 1393 & & \\
\hline & & & & & Efficiency [\%] & 99.50 & 99.51 & 99.42 & 99.30 & & \\
\hline \multirow{4}{*}{1200} & \multirow{4}{*}{ SiC FET } & \multirow{4}{*}{ UF3SC12009K4S × 6} & \multirow{4}{*}{$800 \mathrm{~V}$} & \multirow{4}{*}{$8 \mathrm{kHz}$} & $P_{\text {condition }}[\mathrm{W}]$ & 45 & 180 & 405 & 720 & 1127 & 1621 \\
\hline & & & & & $\mathrm{P}_{\text {switching }}[\mathrm{W}]$ & 265 & 293 & 327 & 368 & 415 & 469 \\
\hline & & & & & $P_{\text {total }}[W]$ & 310 & 473 & 732 & 1088 & 1542 & 2090 \\
\hline & & & & & Efficiency [\%] & 99.38 & 99.53 & 99.51 & 99.46 & 99.23 & 98.96 \\
\hline \multirow{4}{*}{1200} & \multirow{4}{*}{ SiC FET } & \multirow{4}{*}{ UF3SC120009K4S × 4} & \multirow{4}{*}{$800 \mathrm{~V}$} & \multirow{4}{*}{$16 \mathrm{kHz}$} & $\mathrm{P}_{\text {condition }}[\mathrm{W}]$ & 67 & 270 & 608 & 1080 & & \\
\hline & & & & & $P_{\text {switching }}[W]$ & 370 & 436 & 521 & 625 & & \\
\hline & & & & & $P_{\text {total }}[W]$ & 437 & 706 & 1129 & 1705 & & \\
\hline & & & & & Efficiency [\%] & $99.13 \%$ & $99.29 \%$ & 99.25 & 99.15 & & \\
\hline
\end{tabular}

TABLE 2 Total conduction $\left(P_{\text {total }}\right)$ and switching losses $\left(P_{\text {switching }}\right)$ of IGBTs and SiC FETs in electric vehicles (@ UnitedSiC) 
consistently achieve nearly a fourfold reduction in power loss at the typical 50 to $100 \mathrm{~kW}$ level and a near threefold reduction at $200 \mathrm{~kW}$. In electric vehicle applications, lower losses equate to more energy available to the traction motors, which contributes to extending the range. Higher efficiency also translates to lower cooling requirements. This leads to smaller designs with simpler and lighter heat sinks, resulting in a lower overall weight, which also contributes to a higher range. The availability of low on-resistance devices in low-cost discrete packages will enable both a more efficient and economical approach to inverter design.

This is especially true with the advent of generation-4 SiC FET devices. For example, in comparison to $\mathrm{SiC}$ Mosfet, fourth-generation SiC FETs can achieve $50 \%$ better Figure of Merit (FoM) at $25{ }^{\circ} \mathrm{C}$ and $40 \%$ at $125^{\circ} \mathrm{C}$. This is particularly pertinent in hard-switching applications where output capacitance $\mathrm{C}_{\mathrm{Oss}}$ is discharged rapidly from a high voltage, resulting in high transient energy dissipation.

Another SiC FET benefit is that they are robust under short circuit conditions. The short circuit current is set by the JFET, and is not sensitive to the stacked Mosfet parameters. Through self-heating, the positive temperature coefficient of the JFET channel resistance quickly reduces the short circuit current. This allows the device to sustain longer short circuit time durations before the drive circuitry acts to turn the cascode switch off safely. This effect also makes it easy to connect SiC FETs in parallel with automatic current balancing, aided further by the relative insensitivity of the JFET threshold voltage and reverse recovery characteristics to temperature changes.

\section{ELECTRIC VEHICLE CHARGING}

The charging infrastructure is another crucial element in the adoption of electric vehicles. Fast charging requires high power to be delivered to and managed by the vehicle, which needs a robust onboard charger design. SiC FETs are suitable for use in fast chargers, as they can deliver high efficiency in PFC front ends and the main DC/DC conversion stage.

$\mathrm{SiC}$ diodes are already being used to implement output rectification in high voltage chargers. However, using SiC FETs with low drain-source on-resistance may prove more advantageous. For example, at an operating current of 100 A with a $50 \%$ duty cycle, a SiC diode will have conduction losses of nearly 100W, but the UF3SC065007K4S SiC FET will have conduction losses of just $45 \mathrm{~W}$. In addition, synchronous rectification opens the possibility of bi-directional power flow, allowing the electric vehicle battery to return power to the grid for utility load-leveling for example, with corresponding financial benefits.

\section{BACKWARD COMPATIBILITY}

As the SiC FETs are available in TO-247 three- and four-pin packages, they can be a drop-in replacement for many IGBTs and Si Mosfets in motor drives. This gives a significant boost in efficiency with little change in the circuit, apart from perhaps gate drive resistors and small snubbers to tailor the switching edges. Gate drive voltage requirements are non-critical, typically 0 to $12 \mathrm{~V}$. Other benefits such as reducing existing snubbers for lower loss and removing parallel diodes in designs that were originally IGBT-based could be considered. As with earlier SiC FET generations, the high maximum gate drive voltage of fourth-generation devices allows parts to be retrofitted into existing circuits to change out IGBTs, Si Mosfets and SiC Mosfets with little or no modification to the gate drive arrangement, for an instant boost in performance.

\section{SUMMARY}

Sales of electric vehicles are rising steadily. However, a major shortcoming is currently still the range of the vehicles in purely electric operation. To minimize losses in the transmission of electrical energy and thus increase the range of the vehicles, United Silicon Carbide has developed silicon carbide semiconductors that can be used to realize more efficient electrical drivetrains and power components.

\section{REFERENCES}

[1] iea: Global EV Outlook 2020. Technology report June 2020. Online: https://www.iea.org/reports/global-ev-outlook-2020, access: February 01, 2021 [2] UnitedSiC: SiC FETs. Online: https://unitedsic. com/group/sic-fets/, access: February 01, 2021

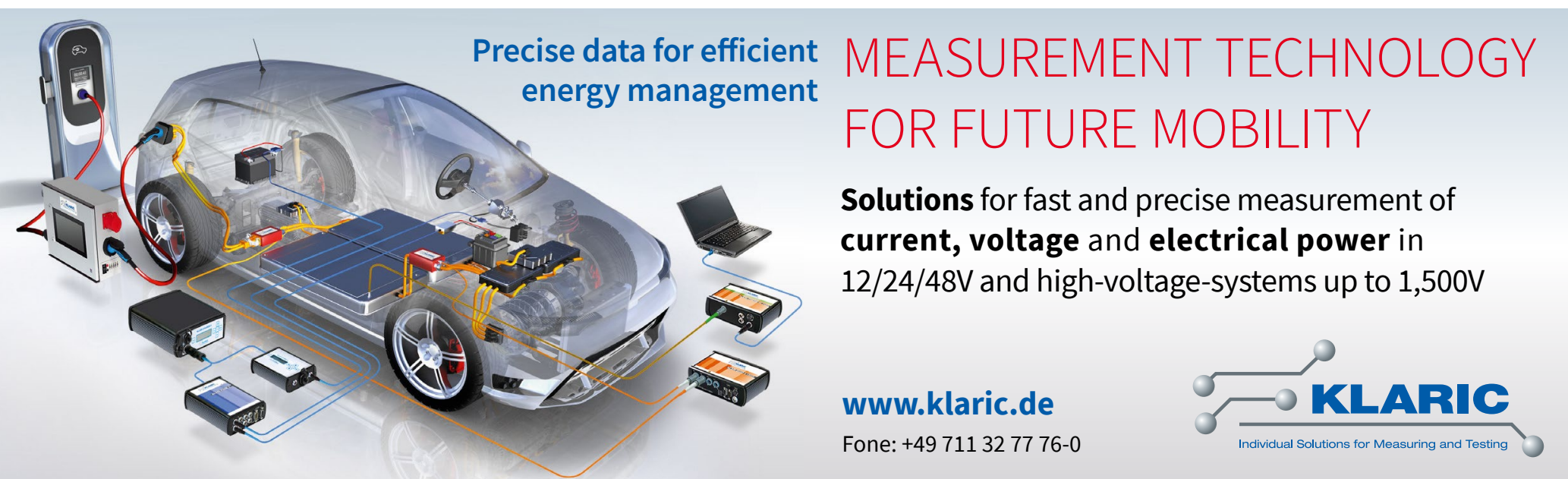

